\title{
In Praise of Gossip: The Organizational Functions and Practical Applications of Rumours in the Workplace
}

\author{
Filippo Ferrari \\ Cà Foscari University, Department of Management, Cannaregio, Venice, Italy \\ Correspondence should be addressed to: Filippo Ferrari; filippo.ferrari@unive.it
}

Received date: 24 July 2014; Accepted date: 6 December 2014; Published date: 15 December 2015

Academic Editor: Salina Daud

Copyright @ (2015. Filippo Ferrari.Distributed under Creative Commons CC-BY 4.0

\begin{abstract}
Workplace gossip is a widespread phenomenon around the world. Nevertheless, organizational literature has paid little attention to gossip and management research surrounding gossip is scarce. Furthermore, almost always, in this field of study, the term "gossip" has negative connotations. However gossip can be an organizational phenomenon both positive and negative at the same time, depending on whether one is viewing gossip from the employee's perspective or the organization's perspective. The aim of this paper is to present some positive applications of gossip, and to provide managers with a deeper understanding of the various functions gossip serves within organizations, in order to reduce specifics costs, improve coordination and control mechanism, and finally provide other benefits.
\end{abstract}

Keywords: Gossip, Coordination Mechanism, Workplace Behaviour, Organizational Justice

\section{Introduction}

Workplace gossip is a ubiquitous phenomenon around the world: research on organizations in both the United States and Western Europe suggests that over $90 \%$ of the workforce engages in at least some gossip activity on the job (Gosser et $\mathrm{al}_{\overline{2}}, 2012$ ). Organizational literature has paid little attention to gossip and, perhaps because of its complexity, management research surrounding gossip is scant (Hafen, 2004; Kurland \& Pelled, 2000; Noon \& Delbridge, 1993). Almost always, in this field of study, the term "gossip" has negative connotations, and some people consider it improper (Kurland and Pelled 2000). In organizational literature, gossip is often considered like a form of aggression (Severance et al., 2013), also from a cross-cultural point-of-view. A paradox of gossip is that it is ubiquitous, though there are numerous social sanctions against it.

However, gossip can be a tricky organizational phenomenon in that it can be both positive and negative at the same time; this often depends on whether one is viewing gossip from the employee's perspective or the organization's perspective (Grosser et al., 2012). 
This paper is organized as follows; first, I try to set down a definition of gossip and its characteristics; second, I intend to provide managers with a deeper understanding of the various functions gossip serves within organizations. I therefore conclude with a discussion of practical actions managers can take to reduce specific costs (i.e. in agency relationship), improve coordination and control mechanisms (i.e. peer monitoring), and provide other benefits (i.e. organizational justice, incident rate, customer satisfaction) by exploiting existing gossip in the workplace.

\section{Gossip and its organizational functions}

Foster (2004) underlines that to function efficiently in a complex social environment, humans require information about those around them. However, there is no denying that gossip, like rumours, "can steal illusions, wreck relationships, and stir up a cauldron of trouble" (Rosnow, 2001, p. 203). Misinformation is also at the heart of condemnations of gossip. An interesting counterpoint to the gossip violates-privacy idea was articulated by Schoeman (1994): for this author, gossip is a 'buffering system' that avoids direct attack of the gossip's target, and manages, at a private level, information that could become public (i.e. in the media).

How much do people gossip? In his review, Foster (2004) estimates that "social topics" concerning either those persons present or third parties were the purpose of conversation about two thirds of the time among both men and women. Emler (1994) reported that about $70 \%$ of conversation time involved gossip. Nevertheless, it is reasonable to conclude that most people spend a non-trivial portion of their interpersonal time gossiping. Several authors (Bergmann, 1993; Eggins \& Slade, 1997; Gluckman, 1963) have remarked that not to gossip (or not to respond to gossipy overtures with at least a modicum of interest) is to be quickly marginalized from local social relationships.
Although it is essentially impossible to eliminate gossip by simply imposing a rule or enforcing an anti-gossip organizational policy, managers need to understand gossip if they hope to manage it and turn it into a profitable tool of management (Grosser et al, 2012).

Obviously, a reputation for too much gossip may also marginalize a person in the workplace. (Bergmann, 1993; Gilmore, 1978; Yerkovich, 1977). Kurland and Pelled (2000) postulated a curvilinear relationship whereby too much or too little gossiping may adversely affect one's referent attractional power.

Everyone knows what gossip is, but it is not so easy to define it. Consistent with a widespread approach in literature, gossip could be defined through several elements. First, the label of gossip is justified primarily by the exchange of information about absent third parties; Besnier (1989) wrote that talk about absent persons is enough to justify the label gossip. Second, the evaluative content: social conversation without value (that is, positive or negative evaluations being made by the gossiper) is essentially the dissemination of human news. Popular understanding of gossip clearly includes a negative evaluative component that, in part, forms the basis for the social sanctions against its practice. Furthermore, most exchanges of personal news carry with them some evaluative meaning implicit in the shared tacit knowledge histories, and cultural norms of the conversationalists (Foster, 2004). Third, situational factors: Spacks (1982) asserted that "it's a certain atmosphere, most of all, that makes gossip recognizable: of intimacy, of gusto, often of surprise and revelation" (p. 30).

In sum, an acceptable definition of gossip is provided by Foster $(2004,83)$ : In a context of congeniality, gossip is the exchange of personal information (positive or negative) in an evaluative way (positive or negative) about absent third parties. 


\section{Social functions of gossip}

Stirling remarked that gossip can also be "an outlet for hostile aggression" (Stirling, 1956, p. 263). Since her article, the social functions of gossip encountered repeatedly in gossip literature over the years are information, entertainment, friendship (or intimacy), influence, evolutionary utility, dynamic utility and guilt by releasing pentup emotions (for a review, see Foster, 2004). Not all these functions are related to the theme of this paper, but it is important to note that any one gossip exchange can serve more than one function simultaneously (Grosser et al, 2012).

As a mechanism of information exchange, gossip is frequently described as an efficient and, at times, exclusive means of gathering or disseminating information (Foster, 2004). Baumeister et al. (2004) agree that social status may be elevated by gossiping: frequently, listeners infer that the gossiper is in possession of special knowledge or understanding of social rules and standards. From the tradition of social exchange in psychology, gossip is often portrayed as a kind of currency, traded like any other, and assessed for its value by the taker on the basis of timeliness, usefulness, and especially, rarity. Rosnow and Fine (1976) observed that the transactional nature of gossip seemed to parallel traditional patterns of economic exchange. Yerkovich pointed out that "information, no matter how salient or scandalous, is not gossip unless the participants know enough about the people involved to experience the thrill of revelation" (Yerkovich, 1977, 196).

Regarding social influence and evolutionary utility, Enquist and Leimar (1993) and Dunbar (2004) maintain that gossip is a kind of informal policing device for controlling free riders and social loafers. In fact, these authors posit that, evolutionarily, this is the most important function of language in general and gossip in particular. Furthermore, co-workers learn what is expected of them by hearing stories holding high performers up to praise and low performers to shame; the "corporate culture" in an organization is commonly expressed this way in gossip stories (Kurland, Pelled, 2000; Noon \& Delbridge, 1993). Baumeister et al. (2004) present evidence that a primary function of gossip is cultural learning in a general form. Such people are repositories of group norms, and their opinions therefore have more weight in shepherding conformity. Conformity is essential for the survival of the group as a whole, which may account for the particularly vitriolic form of gossip observed in groups under pressure to survive and in open competition with one another (Cox, 1970; Gluckman, 1963).

Finally, gossip often allows a cathartic release from anger, guilt, anxiety, or some other unpleasant internal state and a return to a balanced state of repose (Foster, 2004). High levels of emotional labour indicate that there is a discrepancy between what an individual is feeling internally and the emotion that he or she must display. Pent-up emotions arising from emotional labour find a kind of safety valve, especially so when the gossiper cannot directly address the third party that is the target of gossip (i.e. a patient, or a client). This venting can help to reduce stress and feelings of anxiety.

\section{Practical applications}

\section{Reducing agency costs}

First, an application of gossip could be to reduce control costs. In particular, Agency Theory describes the exchange relationship between an actor (the Principal) who delegates to another actor (the Agent) the discretionary power (i.e; decision-making responsibilities) to act on behalf of the Principal for reward (Jensen, Meckling, 1976; Ross, 1973). This relationship aims to align the objectives of the Agent to those of the Principal, in order to reach the desired effect (for a review, Eisenhardt, 1989).

Characteristics of Agency Relationship are well known in literature: bounded rationality of actors involved; different risk aversion between Principal and Agent; uncertainty (the output depends not only on the agent; potential opportunism of the 
Agent; partial goal conflict among participants; information as a purchasable commodity, and, finally, informational asymmetry between Principal and Agent to the benefit of the latter (Eisenhardt, 1989).

In Agency Relationship, the content of gossip useful for the Principal is of course the Agent's behaviour (in this case, the Agent is the absent third part). Due to the widespread diffusion of gossip in organizations and mechanisms of peer monitoring, information about an Agent is usually copious and cheap. The AT economic model should be used in considering the consequences of information resulting from gossip. In studies of Agency Theory (Jensen e Meckling, 1976), it has been well known that when a Principal has information in order to investigate the Agent's behaviour, it will be more likely the Agent acts according to the Principal's interest.

From this point of view, gossip is both an effective and efficient tool to collect information. Managers are often willing to sacrifice assurances of reliability in order to get timely information, and gossip is a primary vehicle by which this information travels (Mintzberg, 1989). Gossip is timely and can be an efficient means by which to get updates about those in one's social network.

\section{Improving coordination mechanisms}

A second application of gossip is in the field of coordination. Organizational literature describes a number of coordination mechanisms, all aimed at ensuring that, in an organization, the right actions are carried out at the right time and in the right place and by the right people (Roberts, 2004). This issue is so relevant that, for some authors, coordination is synonymous with organization (Hatchuel, 2002). The coordination mechanisms most studied are direct supervision, standardization by procedures, skills, outputs, and culture.

Direct supervision. Important elements in this mechanism (well known since Fayol's studies in the early 20th century) are amplitude of supervision (it depends on how many Agents it is necessary to control at the same time), and a number of hierarchical levels involved (Fayol, 1917). It is obvious that the effectiveness of direct supervision is affected by a supervisor's physical and cognitive limits, especially when a supervisor has to manage several jobs at the same time.

Standardization by skills seeks to provide an a priori definition of the range of skills that must be possessed by people fulfilling given roles. This is a coordination method typical of organizations possessing explicit, codified skills sets which are easily replicable and transferable (Grandori, 1992). This mechanism, while making it possible to deal with situations marked by complexity and high-level professionalism, is also a preventative control method and its practical effectiveness is limited in eccentric and unexpected situations.

Procedural standardization implies an a priori definition of performance (March, 1993) or routine programs the operator must adhere to. Performance programs function well when the environment is stable and predictable, and they represent an "organizational memory" (Olson et al., 2005), yet, they reveal insurmountable limits in conditions of uncertainty or in the presence of bounded rationality, since they do not provide the operator with a strategy for dealing with unexpected situations. Also, routines generate expectations about the environment which in turn cause a selective perception of information, thus limiting the knowledge of that environment (Weick, Sutcliffe, 2007).

Standardization by output implies an a priori definition of the results that are to be achieved. It is a control mechanism based on greater autonomy of the operator, who is permitted margins of discretion even within the constraints that characterize the primary work system. In general, this mechanism proves effective (Merchant, Riccaboni, 2001) when the results that are to be achieved are known and accurately definable in advance, in a positive sense, or, as in the case of reliable organizations, in a negative sense (what it is desired to be avoided at all costs). 
Standardization by culture. Without doubt, this is the most powerful but also the most expensive mechanism of coordination and control. Standardizing a culture, in fact, means to act to a deep level relating to shared values, among an organizational population, often changing and setting implicit and unconscious norms (Gagliardi, 1992; Schein, 1999).

In order to align the Principal's and Agent's goals, direct supervision and standardization by output are the most effective mechanisms. Unfortunately, in complex organizations, and without a Management of Objectives system, it is not possible to use these mechanisms. Gossip can improve standardization by culture: in fact, organizational gossip can also be indicative of what is acceptable within an organization and what is not. Gossip can maintain a group's norms and values by circulating judgemental information about deviant group members, maintaining conformity and control over individuals.

\subsection{Improving organizational justice and customer satisfaction}

The participants in an organization obviously want benefits, economic and otherwise, but also something else: they want organizational justice (0J); that is the perception of the moral quality of how they are treated by the organization and by its other members. OJ has been much studied in recent years, and was the subject of two meta-analyses at the beginning of the century (Cohen-Carash, Spector, 2001; Colquitt et al, 2001). These authors, based on the existing literature, point out that the members of an organization assess, with regard to justice, four different aspects: criteria for the distribution of resources (distributive justice); procedures relative to distribution of resources (procedural justice), justice arising from interpersonal relationships (relational justice) and justice relative to information sharing and diffusion (informational justice). As for the possible reactions of a worker who perceives his situation as unjust, these are likely to be reduced commitment (Akerlof, Yellen, 1990; Nosenzo, 2011) and even sabotage of fellow workers (Bartling, von
Siemens, 2010). The perception of injustice can increase employee turnover and, probably, absenteeism (Schwarzald et al., 1992).

Gossip fosters interpersonal intimacy, and in turn improves relational and informational justice. Research shows that individuals who share their negative attitudes about third parties feel closer to one another as a result. When an individual divulges negative gossip, a message is implicitly sent to the recipient that the gossiper trusts him or her, and this is an effective way to strengthen a bond between two people.

Another important consequence of $\mathrm{OJ}$ is the improvement of customer satisfaction. Workers with high level of perceived organizational justice show a high level of Organizational Citizenship behaviour(s), such as; work motivation, punctuality, customer care, that in turn cause high levels of customer satisfaction, especially in front-office workers (Cropanzano, Bowen, Gilliland, 2007).

\subsection{Reducing incident rate}

While gossip fosters organizational culture, at the same time it sets a strong control mechanism. In some specific cases, for example safety and security, gossip could provide help to face and manage undesirable situations. In the field of workplace security, one of the biggest unresolved problems is near misses (a narrowly avoided accident or incident). The laws on workplace security differentiate between accidents (an event with physical damage and/or illness) and incidents (an unexpected, negative event, without physical damage). While accidents are well-investigated, due to mandatory law and formal complaints, on the other hand the monitoring of incidents is more difficult, due to the widespread victimblame approach, and of course the situation is almost always dramatic for near misses.

Gossip can help to obtain information about these events, and so near misses could become an important source of 
learning, and a warning for the future behaviour of workers.

\subsection{Breaking 'ceiling glass'}

Using a Machiavellian approach, gossip is power (Kurland \& Pelled, 2000). Gossip can affect the amount of informal power one has within an organization. Power in this context can be thought of as an individual's ability to influence others to do things that they would not otherwise do. Individuals can use gossip to change or affect attitudes and opinions about others: this makes the process of gossip a process of social influence.

Literature (Grosser et al, 2012) shows that gossip can be used by individuals and groups that occupy positions of low status to exert informal power. For example, gender inequality was still very much evident in many western organizations at the turn of the $21^{\text {st }}$ century. Research in a Japanese context (a very traditional one) shows that; 'the males in these firms feared the gossip among ladies and therefore made attempts to stay on their good side by doing things like frequently taking them to lunch and even bringing them expensive gifts from their business trips abroad (Grosser et al, 2012, 55). This case provides a good example of how one relatively low status group can use gossip to counterbalance formal power differentials.

In summary, gossip leads to influence because it can alter reputations, cause recipients to view gossipers as more powerful, and elevate the relative status of strategic gossipers.

\section{Conclusion}

This paper presents, without doubt, an over-simplification of gossip, but this fact is due to the attempt to counterbalance the traditional, blaming approach to gossip. Prior authors, (ongoing cited), have shown several positive outcomes of gossip in the workplace, grounding their studies on the psychological and anthropological fields of research, and well defining the social functions of gossip. This paper is an attempt to go beyond the simple identifications of social functions, suggesting some practical implications and consequences of these social functions in a workplace context.

Although the use of gossip as a managerial tool is fraught with difficulties and presents counterproductive effects, ongoing cited literature (Severance et al., 2013) shows that gossip has many undesirable effects on the workers' well-being and the perceived organizational justice. Despite these negative aspects, gossip is ubiquitous, even in an era of widespread and pervasive social networks that could do without faceto-face relationships. In the late $90 \mathrm{~s}$, before Twitter and Facebook, Emler (1997) suggested that in gossip there is reciprocity, intimacy, immediacy and lot of previous shared information. In a restricted social group (a peer-group, an organization, a club), the target of gossip is always a close friend. Unfortunately, for an organizational purpose, better information (in terms of truth and validity) is provided by the target's best friend, and this fact contrasts with the informal rules of fairness and friendship (i.e. not to speak badly about friends, not to publicize their confidences). One's best friend is the most valid source of gossip, and so in organizations, gossip becomes a conspiracy of friends against friends. This could be the biggest limitation of gossip's widespread use in the workplace but, luckily, in the workplace there are no friends...

\section{References}

1. Akerlof G.A., Yellen J.L. (1990). 'The Fair-Wage Effort Hypothesis and Unemployment'. Quarterly Journal of Economics, 105, 255-283.

2. Bartling B, von Siemens FA., (2010), 'The Intensity of Incentives in Firms and Markets: Moral Hazard with Envious Agents', Labour Economics, 17, 3, 598-607.

3. Baumeister R. F., Zhang, L., Vohs, K. D. (2004). ,Gossip as cultural learning'. Review of General Psychology, 8, 111-121. 
4. Bergmann J. R. (1993). Discreet indiscretions: The social organization of gossip. Aldine de Gruyter, New York:

5. Besnier N. (1989). 'Information withholding as a manipulative and collusive strategy in Nukulaelae gossip'. Language in Society, 18, 315-341.

6. Cohen-Charash Y., Spector P.E. (2001). 'The role of justice in organizations: A meta-analysis'. Organizational Behavior and Human Decision Processes, 86, 278321.

7. Colquitt J.A., Conlon D.E., Wesson M.J., Porter C.O.L.H., Ng K.Y., (2001), 'Justice at the millennium: A meta-analytic review of 25 years of organizational justice research', Journal of Applied Psychology,86, 425-445.

8. Cox B. A. (1970). 'What is Hopi gossip about? Information management and Hopi factions'. Man, 5, 88-98.

9. Cropanzano R, Bowen DE, Gilliland SW, (2007) 'The Management of Organizational Justice", Academy of Management Perspectives, 21, 34-48.

10.Dunbar R. I. M. (2004). 'Gossip in evolutionary perspective'. Review of General Psychology, 8, 100-110.

11.Eggins S., Slade, D. (1997). Analyzing casual conversation. Cassell, London.

12.Eisenhardt K.M., (1989), 'Agency Theory: An Assessment and Rewiew', Academy of Management, 14 (1), 57-74.

13.Emler N. (1994). Gossip, reputation and social adaptation. In R. F. Goodman \& A. Ben-Ze'ev (Eds.), Good gossip (pp. 119140). University Press of Kansas. Lawrence:

14.Emler N, (1997), La reputazione sociale, in Moscovici, S. , a cura di, (tr. it. 1997), La relazione con l'altro, Cortina, Milano.

15.Enquist M., Leimar O. (1993). ,The evolution of cooperation in mobile organisms'. Animal Behaviour, 45, 747-757.
16.Fayol H. (1917), Administration industrielle et générale; prévoyance, organisation, commandement, coordination, controle, H. Dunod et E. Pinat, Paris.

17.Foster E.K. (2004), 'Research on Gossip: Taxonomy, Methods, and Future Directions', Review of General Psychology, Vol. 8, No. 2, 78-99

18.Gagliardi P. (1992), Le imprese come culture, Isedi, Torino.

19.Gilmore, D. (1978). 'Varieties of gossip in a Spanish rural community'. Ethnology, 17, 89-99.

20.Gluckman, M. (1963). 'Gossip and scandal'. Current Anthropology, 4, 307-316.

21.Gosser Travis J., Lopez-Kidwell V., Labianca G., Ellwardt L.(2012), 'Hearing it through the grapevine: Positive and negative workplace gossip', Organizational Dynamics 41, 52-61

22.Grandori A. (1992), L'organizzazione delle imprese industriali e commerciali, in L. Guatri (a cura di), Economia delle aziende commerciali e industriali, Egea, Milano.

23.Hafen S. (2004). 'Organizational gossip: A revolving door of regulation and resistance'. Southern Communication Journal, 69: 223-240.

24.Hatchuel A. (2002), Coordination and control, in A. Sorge, Organization, Thomson Learning, London.

25.Jensen M., Meckling W.H. (1976). ,Theory of the firm: Managerial behavior, agency costs', and ownership structure. Journal of Financial Economics, 3, 305-360.

26.Kurland N.B., Pelled L.H. (2000). 'Passing the word: Toward a model of gossip and power in the workplace'. Academy of Management Review, 25: 428438.

27.March J.G. (1993), Decisioni e organizzazioni, Il Mulino, Bologna. 
28. Merchant K.A, Riccaboni A. (2001), Il controllo di gestione, McGraw-Hill, Milano.

29.Henry Mintzberg, 1989, Mintzberg on Management: Inside Our Strange World of Organizations, Free Press, Glencoe.

30.Noon M. Delbridge R. (1993). 'News from behind my hand: Gossip in organizations'. Organization Studies, 14: 23-36.

31. Nosenzo D., (2011), 'The Impact of Pay Comparisons on Effort Behavior', CeDEx Discussion Paper n.2010-03, Centre for Decision Research and Experimental Economics at the University of Nottingham, Nottingham, U.K,.

32.Olson E.M., Slater S.F., Hult G.T. (2005), 'The importance of structure and process to strategy implementation', in Business Horizons, 48 (1), 47-54.

33. Roberts J. (2004), The Modern Firm: Organizational Design for Performance and Growth, Oxford University Press, Oxford

34.Rosnow R. L., Fine G. A. (1976). Rumor and gossip: The social psychology of hearsay. Elsevier, New York:

35. Rosnow R. L. (2001). Rumor and gossip in interpersonal interaction and beyond: A social exchange perspective. In R. $M$. Kowalski (Ed.), Behaving badly: Aversive behaviours in interpersonal relationships (pp. 203-232).: American Psychological Association. Washington, DC
36.Ross S., (1973), 'The economic theory of agency: The principal's problem', American Economic Review, 63, 134-139.

37.Schein E (1999), The Corporate Culture Survival Guide, John Wiley \& Sons, New York.

38.Schoeman F. (1994). Gossip and privacy. In R. F. Goodman, A. Ben-Ze'ev (Eds.), Good gossip (pp. 72- 82): University Press of Kansas, Lawrence

39.Schwarzwald J, Koslowsky M., Shalit B., (1992), 'A Field Study of Employees' Attitudes and Behaviors After Promotion Decisions', Journal of Applied Psychology, 77, 511-514.

40.Severance L., Wrzosinska L.B., Gelfand M.J., Lyons S., Nowak A., Borkowski W., Soomro N., Soomro N., Rafaeli A., Treister D.E., Lin C.C. and Yamaguchi S.(2013), "The psychological structure of aggression across cultures', Journal of Organizational Behavior, 34 , 835- 865.

41.Spacks P. M. (1982). 'In praise of gossip'. Hudson Review, 35, 19-38.

42.Stirling, R. B. (1956). 'Some psychological mechanisms operative in gossip'. Social Forces, 34, 262- 267.

43.Weick K.E, Sutcliffe, K.M (2007), Managing the unexpected. Resilient performance in an age of uncertainty, Wiley, NJ.

44.Yerkovich S. (1977). 'Gossip as a way of speaking'. Journal of Communication, 26, 192-196. 